\title{
The Availability and Efficiency of Health Insurance to Expatriates: Empirical Findings from Saudi Arabia
}

\author{
Hashem Abdullah AlNemer ${ }^{1}$ \\ ${ }^{1}$ University of Jeddah, Jeddah, Saudi Arabia \\ Correspondence: Hashem Abdullah AlNemer, University of Jeddah, Jeddah, Saudi Arabia.
}

Received: January 5, 2018

Accepted: January 25, 2018

Online Published: February 2, 2018

doi:10.5539/ibr.v11n3p58

URL: https://doi.org/10.5539/ibr.v11n3p58

\begin{abstract}
Health Insurance represents the largest sectors among all types of insurance in Saudi Arabia with a Gross Written Premiums of $51 \%$ of the whole insurance market in Saudi Arabia. The high growth of health insurance sector in Saudi Arabia was driven by the obligation mandated by the Ministry of Health "MOH" and Council of Cooperative Health Insurance "CCHI" for expatriates and their families living in Saudi Arabia to have their health insurance, affected mid of 2014. However, the regulations didn't specify the types and quality of health insurance used. The regulations also didn't take into consideration the salaries of the expatriates which might affect their financial positions in case of policy cancelation. No studies have been conducted on the Saudi Arabian health insurance market to explore the efficiency and quality of expatriates' health insurance policy. This paper attempts to fill the gap. The main aim of this study was to explore the availability and efficiency of health care system to expatriates. The quality of health insurance policy relies on the selections made by the employers. The research used qualitative methodology for collection of primary data. A total of 324 responds were received and considered usable for the research. The results were astonishing that most of the participants have their own health insurance policy, however not all service are available to them. Most of the participants clarified that their health insurance policy, did not cover of most of the risk they encountered, it did not cover the medical treatment expenses, as well as the surgery and operation expenses. Such results will put financial burden on expatriates in case their health insurance claims been canceled.
\end{abstract}

Keywords: Saudi Arabia, mandatory health insurance, expatriates

\section{Introduction}

Health services in Saudi Arabia have increased and improved significantly during recent decades (Walston et al., 2008). The first public health department was established in Mecca in 1925 based on a royal decree from King Abdulaziz (Alharthi, 1999). This department was responsible for sponsoring and monitoring free health care for the population and pilgrims through establishing a number of hospitals and dispensaries. While it was an important first step in providing curative health services, the national income was not sufficient to achieve major advances in health care, the majority of people continued to depend on traditional medicine and the incidence of epidemic diseases remained high among the population and pilgrims (Alharthi, 1999). When oil income started to rise by 1949 , the general government expenditure was increased including healthcare expenditure. Hence, by 1950 the Ministry of Health was established under another royal decree. MOH was responsible with the overall responsibility for health care in Saudi Arabia and the medical treatment became free for Saudi and non-Saudi residents alike. The $\mathrm{MOH}$ is responsible for managing, planning and formulating health policies and supervising health programmes, as well as monitoring health services in the private sector (Al-Yousuf et al., 2002). It is also responsible for advising other government agencies and the private sector on ways to achieve the government's health objectives (Mufti, 2000). Twenty years later, the 5-year development plans were introduced by the government to improve all sectors of the nation, including the Saudi health care system (Mufti, 2000). Since then, substantial improvements in health care have been achieved and health care services in Saudi Arabia have been given a high priority by the government. Hence, in accordance with the Saudi constitution, the government provides all citizens and Expatriates working within the public sector with full and free access to all public health care services (Aldossary, 2008; Jannadi B et al., 2008). Hence, the Saudi health care sector is the largest in the Near East. Education and healthcare spending still accounts for the largest share of the Saudi 2016 budget, at more than 35 percent of the total budget. With the drop in oil revenues, the Saudi Government scaled back the 
levels of spending across the board, and the budget for healthcare and social development was reduced by 34 percent in 2016, from \$42.67 billion in 2015 to \$27.97 billion in 2016 (MOH, 2016). The budget included several aspects, including a compensation of employees, commodities and services, social benefits, programs expenditures, project expenditures and other expenses. However, with the new regulations which make it mandatory for all private businesses to provide medical insurance for their workers and families, including Saudis and expatriates. The Gross Written Premiums (GWP) for the Saudi insurance market in 2016 reached SR 36.85 Billion, up from SR 36.49 Billion in 2015. Of which health insurance GWP represents $51 \%$ of the insurance market of SR 18.6 Billion in 2016 (SAMA, 2016). Figure 1, illustrates overall insurance gross written premiums by sectors.

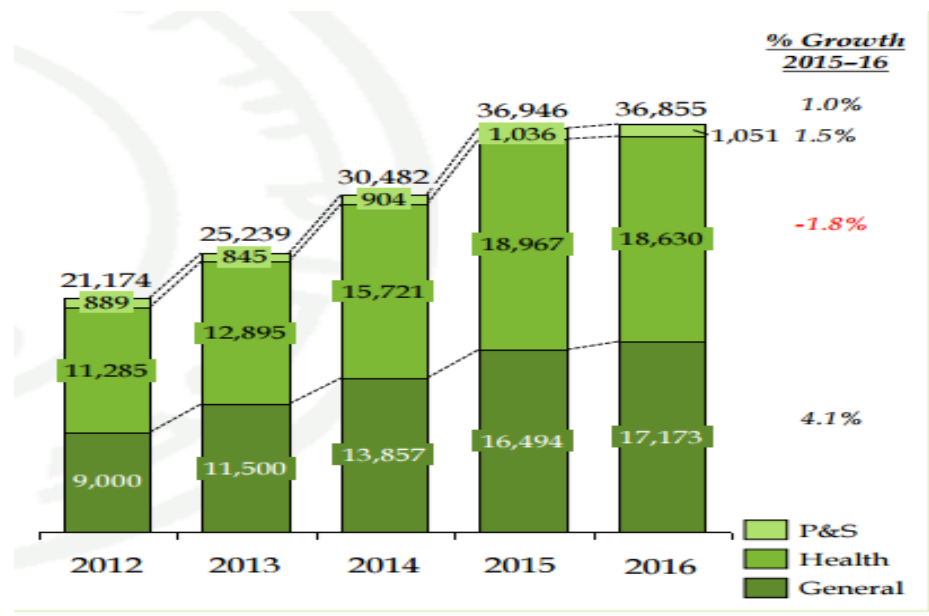

Figure 1. Insurance Market Gross Written Premiums (2012 to 2016, SR Millions)

Source: (SAMA, 2016)

On the other hand, there is a link between the Compulsory Employment-Based Health Insurance "CEBHI", Private and Public Health Insurance. Saudi Arabia reformed its private healthcare system through the CEBHI. The Organization for Economic Co-operation and Development (OECD) distinguishes public from private insurance on the basis of the source of funds (Jost, 2001). Private health insurance is often characterized as voluntary for-profit commercial coverage in contrast to mandatory, publicly financed and publicly managed insurance (ALKHAMIS, 2013). Ultimately, all money comes from household or employer income, but in public insurance programs, this money is channeled through the state via general or social insurance tax, whereas in private insurance the money is paid directly to the risk pooling entity (Sekhri and Savedoff, 2005). The CEBHI shares the nature of the health plan with public insurance (mandatory) and shares with private health insurance the source of funds. In addition, according to Saudi cooperative health insurance, it is not permitted for a health insurance company to reject any application for cooperative health insurance, but health insurance companies provide coverage based on risk pooling, similar to the voluntary health insurance. CEBHI also shares the way premiums are set with private health insurance, based on the expected risk of an individual rather than income; private health insurance and the CEBHI link premiums to the health status of the member and if he/she has a spouse or children (ALKHAMIS, 2013).

\section{Literature Review and Hypotheses Development}

Saudi Arabia is a country that is characterized as a high-income government, under-developed healthcare systems, including healthcare financing, and dominant expatriate populations. The expatriate population dominates the workforce in the private sector in Saudi Arabia, comprising approximately $90 \%$ of the total workforce (Ministry of Labour, 2009, 2009a, 2009b).

The health status of an expatriate is expected to be good for two reasons. One, their average age is 36 years old and two, they are required to undergo two rounds of medical examination as part of the requirements for securing a work visa (Ministry of Labour, 2006b). The first medical is conducted at the home country as part of the requirements for obtaining a work visa, and the second is conducted upon arrival into the Kingdom (Ministry of Labour, 2006a, 2006b).

Leading companies and large companies provide health insurance as part of their employment packages. However, health insurance coverage differs from one company to another (Mufti, 2000). Some companies have 
traditionally provided their own clinics, where employees can receive medical care, and when an employee's health requires a secondary level of care or requires inpatient services, the clinic would arrange the necessary care through other services. Some companies have traditionally signed a contract with an external healthcare provider to provide medical care for their employees (Al-Rabeeah, 2000).

The scope of the medical care coverage varies from one employer to another; whilst some employers provide full coverage by either cash through insurers or via full reimbursement, some firms make reimbursement following the employee having accessed medical services. The reimbursement percentage varies from one company to another (Al-Yousuf, 2002). Other companies do not pay for their workers' medical care expenses; workers in these companies are responsible for paying for their own medical services (Al-Rabeeah, 2000). Therefore, it was expected that employers would vary in their actions towards complying with the new law, and subsequently this would impact on their expatriate employees' access to medical care. However, after the implementation of CEBHI, it is prohibited for any employer not to participate in CEBHI even those involved in private healthcare (CCHI, 2009a, 2009b). After CEBHI, the only two ways to access medical care for expatriates are: Through Health Insurance, health insurance providers offer different health insurance programs starting from the basic plan (each insurer uses a different name for such plans, including C Plan or Balsam Direct) up to the highest level or elite plan (VIP, Gold Balsam), each with a corresponding maximum limit (Bupa, 2010, Al-Yousuf, 2002, Elhout, 2010).

It is noted that those having the highest class of insurance category, can access all types of healthcare provider; whereas those having the lowest insurance category, have very limited access, i.e. general hospitals only (Bupa, 2010, Elhout, 2010, Elhout, 2010). In all programs, expatriates could attend one of their listed hospitals directly without going through a referral system. However, not all clinical services are available in all hospitals (Bupa, 2010; Elhout, 2010; ALKHAMIS, 2013).

Despite the fact that the rules and regulations are there to assure expatriates accessibility to health care and health insurance services, numbers of expatriates face difficulties to do so. It's also noted that several researchers have developed different models in order to identify the main components that influence access to medical care (Andersen, 1968, Green and Krueter 1991, Becker, 1974, Fishbein and Ajzen, 1975, Tanahashi, 1978). However, Andersen has developed a model that brings together different factors in one model to assess the use of health services making it one of the most acceptable models, not only in developed countries but also in developing countries (Buor, 2004, Sunil et al., 2006, Liao, 2008). Anderson suggested that the use of healthcare services is a function of a person's predisposing characteristics. Predisposing characteristics include elements like demographics (such as age, gender), social structures (as determined by a person's status in a community traditionally measured by education, occupation and ethnicity, coping capabilities when presented with problems and resources available to deal with these problems), health beliefs (a person's beliefs about health and health services) and genetic or psychological characteristics (such as mental dysfunctions, cognitive impairment and autonomy) (Andersen, 1995). the presence or absence of enabling resources and need for care (Andersen, 1995). Hence, it's a vital to explore the view and opinion of expatriates about health care and health insurance services in Saudi Arabia via the following hypothesis:

H1- Employers are complying with the regulations to medically insure workers in Saudi Arabia.

The CCHI has issued new regulations that require all private sector employers to register their employees and their dependents under a single policy for mandatory health insurance. After the implementation of CEBHI, the methods of accessing medical care services changed. According to Cooperative health insurance law, it is prohibited for any employer not to participate in CEBHI even those involved in private healthcare (CCHI, 2009b). So the signing of contracts and providing services through their own clinics is not acceptable (CCHI, 2009b) After CEBHI.

\section{H2- Expatriates Health Insurance claims have a low rate of rejection?}

It is noted that those having the highest class of insurance category, can access all types of healthcare provider (from healthcare centers and clinics to high-class hospitals or specialized hospitals); whereas those having the lowest insurance category, have very limited access, i.e. general hospitals. The basic health insurance plan has limited affiliated hospitals and clinics, and these are known to provide poorer quality services than those accessible via the VIP or Golden plans. Employees having a VIP or Golden health insurance plan can access all hospitals and clinics including those listed under the basic health insurance plan, but those having a basic health insurance plan, can only access those clinics or hospitals affiliated under their plan (Bupa, 2010, Elhout, 2010). If a patient with a basic plan requires a clinical procedure provided by a healthcare provider not within the affiliated list of hospitals or clinics, permission and referral from their insurer must be obtained. In all programs, 
expatriates could attend one of their listed hospitals directly without going through a referral system. In other words, there is no system that forces expatriate workers to seek medical care at a primary healthcare facility before going to a secondary healthcare facility. However, not all clinical services are available in all hospitals. Therefore, some people having a basic plan may not find all the services (particularly tertiary healthcare) available in their plan, and therefore they must seek the advice of their insurance company (Bupa, 2010, Elhout, 2010).

H3- Health Insurance Policy Covers all kind of exposed risks faces by workers in Saudi Arabia.

leading companies and large companies provide health insurance as part of their employment packages. However, health insurance coverage differs from one company to another (Mufti, 2000). Some companies have traditionally provided their own clinics, where employees can receive medical care, and when an employee's health requires a secondary level of care or requires inpatient services, the clinic would arrange the necessary care through other services (Al-Rabeeah, 2009). Some companies have traditionally signed a contract with an external healthcare provider to provide medical care for their employees (Al-Rabeeah, 2009). In this case the employee would obtain permission from his employer ahead of time before seeking medical care.

H4- Health Insurance covers all expenses faces by labors in Saudi Arabia?

Although CEBHI is compulsory and all expatriates working in the private sector must be insured, those expatriates who are uninsured, for different reasons, have access to medical care only through cash. Expatriate workers can also opt to pay through direct cash payments to providers. Payment schemes can either be out-of-pocket (OOP) employee payments or co-sharing with the employer. In addition, other medical care access options are available, such as companies providing medical care services to their employees by their own company clinics or infirmaries or by contracting healthcare providers to render medical services for workers.

\section{Statement of the Problem}

The Ministry of health and council of cooperative health insurance CCHI has made medical insurance must for expatriates and their families living in Saudi Arabia affected mid of 2014. It's the responsibility of the employer to provide medical insurance to individual and his family living in Saudi Arabia. The coverage is mandatory for all employees irrespective of the salaries they receive. Hence, the main aim of this study is to explore the availability and efficiency of employer's medical care via health insurance to expatriates, which comes in parallel with the efforts exerted by the Saudi government implementing CEBHI compulsory for expatriates.

\section{Objectives of the Study}

The main aim of this study is to explore the availability and efficiency of health care system to expatriates.

\section{Methodology}

The research used a qualitative methodology, with a primary data collection. The targeted people were expatriates working in the private sector. The questionnaires were structured and close-ended. The questionnaire was developed in English and translated into Arabic language. The translation was done to facilitate and encourage expatriates who speaks Arabic languages only. The translation also to some extent enhanced the reliability of the information provided. A drop-off of a self-administered survey questionnaire and telephone calls techniques were used to collect participants' responses. Accordingly, a total of 500 questionnaires were distributed, of which 383 completed questionnaires were received, where 59 questionnaires were rejected, leaving 324 completed and usable questionnaires for the research, yielding a usable response rate of $85 \%$. The closed-ended or forced-choice type of question is preferable in this research because it will increase the response rate, since it is easier and faster to be answered by the prospective respondents. The responses yielding a usable rate reflected the success of using these types of questionnaires. To attain the aims and objectives of the study, a descriptive analytical tools such as frequency, percentage, were used to summarize the respondents' feedback. In the following sections empirical results are presented and discussed.

\section{Results and Discussions}

This section presents the research results related to the objectives of the study proposed earlier. The reliability of research results depends on the reliability of empirical data. Reliability was evaluated by assessing the internal consistency of the items representing each factor using Cronbach's Alpha. The Cronbach Alpha value for first is $(0.867)$ which is acceptable. Thus data on these variables are reliable and consistent with research standards. 
Table 1. Companies Adherence to the Healthcare Regulations

\begin{tabular}{cccc}
\hline Q1 - Did the company issues a health insurance policy for you. & & \\
\hline & Options & Frequency & Percent \\
\cline { 2 - 4 } Valid & No & 19 & 6 \\
& Yes & 305 & 94 \\
& Total & 324 & 100.0 \\
\hline
\end{tabular}

Table 1, discusses the adherence of companies to the regulations imposed by CEBHI, which made it mandatory for companies to provide health care coverage for their employees. This question also supported the assumptions that been posted by the first hypothesis, which shows the adherence of companies working in Saudi Arabia with the regulations of CEBHI. Hence, 305 (94\%) of the participants have their own insurance policy, which is a strong indicator of the adherence of employer to the CEBHI regulations.

Table 2. Rejection of Health Insurance Policy

\begin{tabular}{cccc}
\hline Q2 - Was the claim of your health insurance policy rejected as a results of a weakness in the insurance coverage? \\
\cline { 2 - 4 } & Options & Frequency & Percent \\
\cline { 2 - 5 } Valid & No & 191 & 59 \\
& Yes & 133 & 41 \\
& Total & 324 & 100.0 \\
\hline
\end{tabular}

Table 2, discusses the efficiency of health insurance policy by viewing number of policies been rejected as a reasons of policy weakness. Hence, $191(59 \%)$ of the participants indicated that their insurance policies never been rejected before. While, $133(41 \%)$ of the participants clarifies that their health insurance policy were rejected, which indicated that a number of expatriates are receiving a basic or poor quality health insurance coverage. In other words, expatriates health insurance plan has limited affiliated hospitals and clinics. The answers to this question didn't match what been assumed on hypothesis two, as $39 \%$ of cancelation rate didn't considered as a low rate of rejection.

Table 3. Validity of health insurance policy to cover different encountered risks

\begin{tabular}{|c|c|c|c|c|c|c|c|c|c|c|}
\hline $\begin{array}{l}\mathrm{Q} 3 \\
\text { to? }\end{array}$ & Does & the & health & insurance & policy & covers & risks & you & are & exposed \\
\hline & \multirow{4}{*}{ Valid } & & \multicolumn{3}{|c|}{ Options } & Frequency & \multicolumn{4}{|c|}{ Percent } \\
\hline & & & \multicolumn{3}{|c|}{ No } & 232 & \multicolumn{4}{|c|}{71.4} \\
\hline & & & \multicolumn{3}{|c|}{ Yes } & 92 & \multicolumn{4}{|c|}{28.6} \\
\hline & & & & Total & & 324 & \multicolumn{4}{|c|}{100.0} \\
\hline
\end{tabular}

Table 3, discusses the efficiency of health insurance. It's vital for health insurance policy to cover most of the risk that expatriates exposed to. Surprisingly, the results show that $232(71 \%)$ of the participants indicated that the company offers a low efficiency health insurance coverage, as the policy didn't covers most of the risks that they exposed to. The answers to this question comes in contrast with the assumptions that stated on hypotheses three. Which assumed that companies in Saudi Arabia provides health insurance policies that covers most of the expatriates exposed risks.

Table 4. The ability of Health Insurance to cover treatment expenses

\begin{tabular}{cccc}
\hline Q4 - Does the health insurance policy covers the medical examination only without covering treatment expenses? \\
\cline { 2 - 4 } & Options & Frequency & Percent \\
\cline { 2 - 4 } Valid & No & 161 & 49 \\
& Yes & 163 & 51 \\
& Total & 324 & 100.0 \\
\hline
\end{tabular}

Table 4, discusses the efficiency of health insurance to cover medical examinations expenses without covering treatment expenses. As not all health insurance policies having the same category and ability to provide different health care services. In other words, not all clinical services are available for expatriates. Surprisingly, 163 (51\%) of the participants indicated that the health insurance policy they have, didn't cover the medical treatment expenses, its only cover the medical expenses. In other words, more than $50 \%$ of the expatriates working in Saudi Arabia have the basic health insurance policy. The view of the participants comes in contrast with the assumptions that been made in hypothesis four. As the health insurance policies provided by the employers didn't covers all medical expenses requested by expatriates.

Table 5. The ability of Health Insurance to cover operation and surgery expenses

\begin{tabular}{cccc}
\hline Q5 - Does the health insurance license covers the operation and surgery expenses. & Percent \\
\cline { 2 - 4 } & Options & Frequency & 52 \\
Valid & No & 167 & 48 \\
& Yes & 157 & 100.0 \\
\hline
\end{tabular}


Similar, to the discussion of the previous question. Table 5, indicated that most of the expatriate's health insurance didn't covers the operation and surgery expenses. As, $167(52 \%)$ of the expatriates indicated that, the health insurance policies they have didn't cover the surgery expenses they exposed to. In other words, half of the employers in Saudi Arabia provided a basic or low quality policies to the expatriates working for them. The view of the participants comes in contrast with the assumptions that been made in hypothesis four. As the health insurance policies provided by the employers didn't covers surgery expenses requested by expatriates.

\subsection{Demographic Profile of the Respondents}

Data was collected from 324 respondents were all of them expatriates working in Saudi Arabia. Approximately $59 \%$ of them having a salary of SR 2000 or less, while $38 \%$ clarified of having a salary between SR "2000 to 4000 ", only $3.4 \%$ had a salary of more than SR 4000. In term of the size of the firm, $28 \%$ of the employees working for small firms with a budget of SR 200,000 or less, $37 \%$ works for a mid-size firms with a budget between SR 200,000 to 1 million, and 36\% works for a large size companies with a budget of more than a million riyals. The reason behind asking about the firm size, is to identify if the firms are capable of providing a highest class of insurance policy, especially those who are categorized as a large company with a great number of employees and budget. The employees also been asked about the number of years they spent working in current company, such question clarifies the level of the employee's satisfactions, the greater the number of working years working for this company the greater the satisfaction level for all services presented by such company. Hence, $49 \%$ of the expatriates had worked for the same company for five years and less, while $27 \%$ of the expatriates had worked at the same company for a period between five to ten years, $24 \%$ had worked for the same company for more than ten years.

\section{Discussion}

The main purpose of this paper is to identify if firms operating in Saudi Arabia are complying with the new regulations posted by $\mathrm{CCHI}$ and $\mathrm{CEBHI}$ which requires private sectors employees and their dependents to be registered under a single policy for a mandatory health insurance. Hence, it was clearly from question one, that almost all companies operating in Saudi Arabia are complying with the CCHI and CEBHI regulations as 94\% of the expatriates got their health insurance policy. Such an answers goes in favor with the assumptions made by hypothesis one which assume the adherence of companies working in Saudi Arabia with regulations made by CCHI and CEBHI. In term of the efficiency of insurance policy to cover most of the claims. $59 \%$ of expatriate's participants clarifies that their policy never been rejected, while the remaining 39\% indicates that the claim they have raised been canceled. Such a results assumes that the policy might be categorized as a basic or limited affiliated hospitals and clinics insurance policy. It's been notified from the demographic paragraph that $28 \%$ of the expatriates works for small companies, also 59\% of them having a low salary of SR 2000 or less. Such an indications assist that these expatriates' qualifications doesn't allows them to possess a high level insurance policy such as VIP or golden ones. However, the answers to this question didn't match what been assumed on hypothesis two, as $39 \%$ of cancelation rate didn't considered as a low rate of rejection. In regards to the efficiency of health insurance, which should cover the majority of risk exposed to. Dramatically, 232 (71.4\%) expatriate's participants indicated that the company offers a low efficiency health insurance coverage, as the policy didn't covers most of the risks that they exposed to. Such an answer assisted the conclusion that most of expatriate's insurance policy are categorized as basic or limited affiliated hospitals since it doesn't cover all risk encountered. However, the answers to this question comes in contrast with the assumptions that stated on hypotheses three. Which assumed that companies in Saudi Arabia provides health insurance policies that covers most of the expatriates exposed risks. In regards to the expenses encountered, surprisingly $51 \%$ of the participants demonstrate that the health insurance policy doesn't covers most of the treatment expenses encountered. Treatment expenses provides insurance against some or all costs of treatment by ancillary health service providers such as "dental treatment, chiropractic treatment, home nursing, glasses and contact lenses, etc". such a results shows a big failure that can lead expatriates to pay out medical expenses from their pocket, as more than half of the expatriates have a basic medical insurance. Similarly, 52\% of the participants, indicated that the health insurance they possess didn't covers the operation and surgery expenses. Again such clarification shows a big defect in covering expatriates' health conditions. Both results of different expenses encountered, comes in contrast with the assumptions that been made in hypothesis four. As the health insurance policies provided by the employers didn't covers all medical expenses requested by expatriates.

\section{Conclusion}

It became mandatory for expatriates working in Saudi Arabia to have their own health insurance policy. Employers are obliged to comply with CCHI and CEBHI regulations to insure their expatriate employees having 
an adequate health insurance policy. However, the regulations didn't specify the types and quality of health insurance used. Therefore, it was vital to explore the quality and efficiency of the services provided by health insurance policies towards expatriates. Hence, a couple of questions been directed to 324 expatriates in regards to the health insurance policies they possess. The results had shown that almost all expatriates have their own health insurance policy. However, a quite good number of the claims been canceled which indicated their health insurance policy are basic ones. Another, unexpected result shows that the majority of participants are unhappy with the policy they possessed as the policy didn't cover all the risk they exposed to. Furthermore, almost half of the expatriate participants clarified that their health insurance policy didn't cover most of the expenses and claim raised, such as treatment and surgery expenses. Hence, it became vital for the regulator of the health care to impose rules and regulations that can reserve expatriates' rights to receive at least the minimum health insurance services including surgery and treatment health care.

\section{References}

Aldossary, A., While, A., \& Barriball, L. (2008). Health care and nursing in Saudi Arabia. International Nursing Review, 55, 125-128.

Alharthi, F. et al. (1999). Health over a century. Riyadh, Ministry of Health and ASBAR Centre for Studies Research and Communication.

Alkhamis, A. (2013). A Comparison Of Access To Medical Care For Insured And Uninsured Expatriates In Saudi Arabia. Unpublished $\mathrm{PhD}$ Thesis, University of Liverpool.

Al-Rabeeah, O. (2000). Cooperative Health Insurance. Is it the best alternative? Cooperative Health Insurance. Dammam, Magrabi.

Al-Yousuf, M., Akerele, T. M., \& Al-Mazrou, Y. Y. (2002). Organization of the Saudi health system. Eastern Mediterranean Health Journal, 8, 645-653.

Andersen, R. M. (1968). A behavioral model of families' use of health services. , Research Series No 25, Chicago: Center for Health Administration Studies, University of Chicago.

Andersen, R. M. (1995). Revisiting the Behavioral Model and Access to Medical Care: Does it Matter? Journal of Health and Social Behavior, 36, 1-10.

Becker, M. H. (1974). The health belief model and personal health behavior. Health Education Monographs, 324-508.

Buor, D. (2004). Gender and the utilisation of health services in the Ashanti Region, Ghana. Health Policy, 69, 375-388.

BUPA. (2010). Bupa`s Products. Jeddah, Bupa. Available from: http://www.bupa.com.sa

CCHI. (2009a). Annual Report. Riyadh, Council of Cooperative Health Insurance. Available from: http://www.cchi.gov.sa/Studies/Reports/AnnualReports/Pages/default.aspx

CCHI. (2009b). Regulations for Cooperative Health Insurance System. IN INSURANCE, T. C. O. C. H. (Ed.) 6131/30/1/z. Riyadh, The Council of Cooperative Health Insurance.

Elhout, A. (2010). MedGulf Health Insurance programs for Workers. Riyadh.

Fishbein, M., \& Ajzen, I. (1975). Belief, attitude, intention and behavior: an introduction to theory and research. Reading, Mass.: Addison-Wesley Pub. Co.

Green, L. W., \& Krueter, M. W. (1991). Health Promotion Planning: An Educational and Environmental Approach, Mayfield Pub Co.

Jannadi, B. et al. (2008). Current structure and future challenges for the healthcare system in Saudi Arabia. Asia Pacific Journal of Health Management, 3, 43-50

Jost, T. S. (2001). Private or Public Approaches to Insuring the Uninsured: Lessons from International Experience with Private Insurance. New York University Law Review, 76, 92.

Liao, H. E. (2008). Initial Effect if the national health insurance program in Taiwan on access to health care. $(\mathrm{PhD})$ Department of Health Baltimore, Maryland. Johns Hopkins University.

Ministry of Health-Oman. (2006). The National Strategic Plan. Muscat Ministry of Health Sultanate Oman: 351. Ministry of Labour (2006a) Labour Law. Riyadh.

Ministry of Labour Ministry of Labour. (2009b). Saudi Labours Market indicators, Riyadh Regions. Riyadh, 
Ministry of Labour, 126.

Ministry of Labour. (2008). Number of the top five nationalities in the private sector by Gender. Riyadh, Ministry of Labour: 139. Ministry of Labour (2009) Annual Report. Riyadh.

Ministry of Labour 120. Ministry of Labour. (2006b). Saudi Strategy for Recruitment Riyadh, Ministry of Labour: 273.

Ministry of Labour: 148. Ministry of Labour. (2009a). Saudi Labour Market Indicators, Riyadh region IN LABOUR, M. O. (Ed.) Saudi Labour Market Indicators. First edition ed. Riyadh.

MOH. (2016). Healthcare Indicator Reports Riyadh, MOH: 445.

Mufti MHS. Healthcare development strategies in the Kingdom of Saudi Arabia. New York, Kluwer Academic/Plenum, 2000.

SAMA (2016). The Saudi Insurance Market Survey Report. Riyadh. Available from: http://www.sama.gov.sa/sites/SAMAEN/Insurance/InssuranceLib/4600_R_InsuaMarketSurvey2016_En_20 16_05_16_V1.pdf

Sekhri, N., Savedoff, W., \& Thripathi, S. (2005). Regulating Private Health Insurance to Serve the Public Interest: Policy Issues for Developing Countries. World Health Organization Discussion Paper Number, 3, 35.

Sunil, T. S., Rajaram, S., \& Zottarelli, L. K. (2006) Do individual and program factors matter in the utilization of maternal care services in rural India? A theoretical approach. Social Science \& Medicine, 62, 1943-1957.

Tanahashi, T. (1978) Health service coverage and its evaluation. Bulletin World Health Organ., 56, 8.

Walston, S., Al-Harbi, Y., \& Al-Omar, B. (2008). The changing face of healthcare in Saudi Arabia. Annals of Saudi Medicine, 28, 243-250.

\section{Copyrights}

Copyright for this article is retained by the author(s), with first publication rights granted to the journal.

This is an open-access article distributed under the terms and conditions of the Creative Commons Attribution license (http://creativecommons.org/licenses/by/4.0/). 